\title{
Physicians and Patients' Awareness About the Risks, Impacts, and Management of Obesity in the Gulf Region; A Cross-sectional Study
}

\section{Salman K Al-Sabah' ${ }^{1}$, Noor Al Busaidi², Dalal Al Romaihi ${ }^{3}$, Mohammad H Jamal ${ }^{4}$, Saud Al Sifri ${ }^{5}$ and Emad R Issak ${ }^{6 *}$}

${ }^{1}$ Director of Surgical Research and Academic Program in the Department of

Surgery, Consultant Surgeon, Al Amiri Hospital, Kuwait

${ }^{2}$ Chairperson, Oman Diabetes Association, Director, National Diabetes and

Endocrine Center. Royal Hospital, Ministry of Health, Oman

${ }^{3}$ Consultant Endocrinologist, King Hamad University Hospital, Bahrain

${ }^{4}$ Associate professor, Kuwait University, Program Director, Kuwait Institute for

Medical Specialization, Kuwait

${ }^{5}$ Chairman of Endocrinology and Diabetes Department Alhada and Taif Armed

Forces Hospitals, Saudi Arabia

${ }^{6}$ Internal Medicine, Researcher, Faculty of Medicine, Ain-Shams University, Cairo,

Egypt

*Corresponding Author: Emad R Issak, Internal Medicine, Researcher, Faculty of

Medicine, Ain-Shams University, Cairo, Egypt.

E-mail: dr.emad.r.h.issak@gmail.com

ORCID: 0000-0003-4150-649X
Received: February 16, 2021

Published: March 05, 2021

(C) All rights are reserved by Salman K

Al-Sabah., et al.

\begin{abstract}
Obesity is a significant health problem that reduces life expectancy and the quality of life. This cross-sectional two-arm study aimed to test the physicians' and individuals' level of awareness of obesity and its consequences. The physicians' arm was conducted upon 104 registered physicians licensed to practice in one of in Gulf cluster countries (Kuwait, Qatar, Oman and Bahrain) who deal with patients with obesity. The obese-patients' arm was conducted upon 2337 patients in the same countries.

The most frequent main modifiable reason for the increase in obesity, according to physicians, is the lack of self-control. Reduction in motivation and lack of compliance is the most likely contributors to weight gain after a period of weight loss. In addition, they see that 10-15 kg weight loss or 5-10\% weight loss from baseline weight gives significant improvements in health in terms of reducing body weight. The most optimal lifestyle treatment strategy is diet, exercise, and CBT. Not all physicians believe that they are responsible for actively contributing to their patient's successful weight loss efforts. The more significant part of the physicians was not aware of their role to educate people with obesity. Physicians are reluctant to initiated talk about weight with patients.

More than half of obese patients mentioned that obesity affects their lifestyle, physical health, social life, and romantic relationships. Obesity increases the risk of developing significant outcomes like arthritis, heart disease, fatty liver, hypertension, and kidney failure. The majority of them view that obesity is a lifestyle choice. They perceived that it is less serious and found it as a cosmetic issue. Financial issues are significant barriers to attempts to lose weight, followed by lack of information. Prescription medications are the most frequent methods that they are currently using or have tried to use in the past to lose weight, followed by diet and exercise and dietary supplements.
\end{abstract}

Keywords: Obesity; Awareness; Outcomes; Management 


\section{Introduction}

Obesity is a significant health problem that reduces life expectancy and the quality of life [1]. According to WHO estimation in 2016, around the world, more than 1.9 billion of those 18-years of age or older were overweight, and over 600 million have been diagnosed as obese [2]. That increase in prevalence has been particularly intense in the Gulf region, like Saudi Arabia, Bahrain, Qatar, Kuwait, Oman, and the United Arab Emirates [3,4].

Gulf countries have the highest rate of obesity. Kuwait, Bahrain, Saudi Arabia, and the United Arab Emirates are in the list of top ten countries worldwide in terms of obesity [2]. The prevalence of obesity in Gulf Countries among children and adolescents ranges from $5 \%$ to $14 \%$ in males and $3 \%$ to $18 \%$ in females. There is a significant increase in obesity in adult females, with a prevalence of $2 \%-55 \%$ and adult males $1 \%-30 \%$ in the Gulf region countries [3].

Also, in Saudi Arabia (KSA), according to the data from the World Atlas about the most obese countries in the world, KSA is the world 14th most obese country, with an overall obesity rate of $35.4 \%$; which has resulted from less regular exercise or physical activities, increased consumption of western fast food, and the use of large community platters $[5,6]$. According to the WHO health profile of Saudi Arabia 2015, which was based on the data from the Saudi Ministry of Health, the prevalence of low levels of physical activity is $60.3 \%$ ( $46.0 \%$ males, $75.1 \%$ females). Obesity affects $28.7 \%$ of the population ( $24.1 \%$ males, $33.5 \%$ females). A serious challenge affecting the country is the rise in childhood obesity, affecting approximately $6-10 \%$ of preschool and school-age children $[7,8]$.

Obesity has a strong association with many risk factors like hormones, high food intake, sedentary lifestyle, low socioeconomic status, and smoking [9].

Else, it is associated with many co-morbidities, including cardiovascular, diabetes, respiratory, sleep apnea, joint diseases, gastrointestinal, and some types of malignancy [10-12]. The increased prevalence of obesity has a disastrous financial burden at the governmental and the individual level $[13,14]$.

Of course, the first step to developing useful interventions to minimize this health problem is estimating the prevalence rate and the level of awareness at the individual level and the health care professional level.

Therefore, this study's rationale was to test the physicians' and individuals' level of awareness of obesity and its consequences.

\section{Methods}

A two-arm (physicians and patients) cross-sectional study. The physicians' arm was conducted upon 104 registered physicians licensed to practice in one of in Gulf cluster countries (Kuwait, Qatar, Oman and Bahrain) who deal with patients with obesity. The survey was emailed to virtually 160 physicians in the Gulf Cluster countries within a healthcare professional panel database (response rate: 65\%). The emails were sent from early February 2020 through early April 2020. The survey included 17 separate MCQs, with multiple responses possible on some questions. The survey was brief (estimated time to complete was 10-15 minutes), and responses were kept anonymous. The total number of surveys received was 104 . The margin of error for all questions was calculated, and it was $+/-1.057 \%$.

The obese-patients' arm was conducted upon 2337 patients in one of the Gulf cluster countries (Kuwait, Qatar, Oman and Bahrain). The survey included 16 separate MCQs, with multiple responses possible on some questions. The survey was brief (estimated time to complete was 10-15 minutes), and responses were kept anonymous. The survey was emailed to virtually 4000 obese patients in the Gulf Cluster countries. The total number of surveys received was 2337 (response rate $=58 \%$ ). The margin of error for all questions was calculated, and it was $+/-1.123 \%$. The purpose of the study was explained to participants at the start of the questionnaire. The final questionnaire was developed after pilot testing among 30 physicians and 100 patients, and necessary modifications were carried out.

The administered questionnaire included the following sections-demographic data including country, gender, age, nationality, and specialty for the physicians' arm. Knowledge of participants was assessed by asking them about different aspects of obesity, including lifestyle, knowledge about morbidity associated with obesity, and management of obesity. For the patients' arm, the administered questionnaire included the following sections: demographic data including country, gender, age, nationality, and BMI.

Knowledge of participants was assessed by asking them about different aspects of obesity, including lifestyle, knowledge about morbidity associated with obesity, and management of obesity.

The survey responses were entered into the SPSS software (version 17.0) and checked for any errors or missing information. Demographic characteristics were assessed using means for continuous variables and proportions for categorical variables. 
Results

Physicians' arm

Demographics

Most (70.2\%) of the 104 enrolled physicians belong to 35-54 years. Almost half of them were male (51.9\%). They are practicing in the four Gulf countries: Kuwait 27.9\%, Bahrain 30.8\%, Qatar $32.7 \%$, and Oman $8.7 \%$. GP and family medicine constituted the majority (66.3\%) of the enrolled physicians (Table 1 ).

\begin{tabular}{|l|c|c|}
\hline & $\mathbf{n}$ & $\mathbf{\%}$ \\
\hline Age Range (Years) & & \\
\hline $35-44$ & 34 & $32.7 \%$ \\
\hline $45-54$ & 39 & $37.5 \%$ \\
\hline $55-64$ & 20 & $19.2 \%$ \\
\hline $65-74$ & 11 & $10.6 \%$ \\
\hline Gender & & \\
\hline Male & 54 & $51.9 \%$ \\
\hline Female & 50 & $48.1 \%$ \\
\hline Country & & \\
\hline Kuwait & 29 & $27.9 \%$ \\
\hline Bahrain & 32 & $30.8 \%$ \\
\hline Qatar & 34 & $32.7 \%$ \\
\hline Oman & 9 & $8.7 \%$ \\
\hline Specialty & & \\
\hline GP & 39 & $37.5 \%$ \\
\hline Family medicine & 30 & $28.8 \%$ \\
\hline Endocrinologist & 26 & $25.0 \%$ \\
\hline Bariatric surgeon & 9 & $8.7 \%$ \\
\hline
\end{tabular}

Table 1: Physicians' demographics.

\section{Physicians' insight into obesity}

The most frequent main reason for the increase in overweight and obesity, according to physicians, is the lack of self-control $(28.8 \%)$ followed by the genetic predisposition in addition to inactivity and overabundance of food (26.0\%). Reduction in motivation and lack of compliance is the most likely contributor to weight gain after a period of weight loss (42.3\%). The least associated comorbidity with obesity, as mentioned by physicians, is osteoporosis $(44.2 \%)$, followed by male infertility $(30.8 \%)$, table 2 .

More than half of the enrolled physicians (55.8\%) reported that body mass index (BMI) represents the current standard diagnostic

\begin{tabular}{|c|c|c|}
\hline & $\mathbf{n}$ & $\%$ \\
\hline \multicolumn{3}{|c|}{$\begin{array}{l}\text { 1. Which of the following statements is the main reason for } \\
\text { the increase in overweight and obesity? }\end{array}$} \\
\hline a) Lack of self-control & 30 & $28.8 \%$ \\
\hline b) Genetics & 15 & $14.4 \%$ \\
\hline $\begin{array}{l}\text { c) Genetic predisposition in addition to in- } \\
\text { activity and overabundance of food }\end{array}$ & 27 & $26.0 \%$ \\
\hline $\begin{array}{l}\text { d) Increasing use of medications that can lead } \\
\text { to weight gain }\end{array}$ & 13 & $12.5 \%$ \\
\hline e) Endocrine causes & 19 & $18.3 \%$ \\
\hline
\end{tabular}

2. Weight gain (WG) after a period of weight loss (WL), is one of the most profound challenges in obesity management. Which of the following statements represents the most likely contributor?

\begin{tabular}{|l|c|c|}
\hline $\begin{array}{l}\text { a) Reduction in motivation and lack of compli- } \\
\text { ance }\end{array}$ & 44 & $42.3 \%$ \\
\hline $\begin{array}{l}\text { b) Reduction in RMR*and a decrease in energy } \\
\text { expenditure related to PA** }\end{array}$ & 20 & $19.2 \%$ \\
\hline $\begin{array}{l}\text { c) Increase in hunger sensation and a decrease } \\
\text { in satiety due to physiological adaptations to } \\
\text { appetite control systems }\end{array}$ & 12 & $11.5 \%$ \\
\hline d) Combination of all of the above & 28 & $26.9 \%$ \\
\hline
\end{tabular}

3. Which diagnostic criterion regarding obesity represents the current standard?

\begin{tabular}{|l|c|c|}
\hline a) BMI $\left(\mathrm{kg} / \mathrm{m}^{\prime}\right)$ & 58 & $55.8 \%$ \\
\hline b) Presence of comorbidities & 27 & $26.0 \%$ \\
\hline c) Body composition (fat-free mass vs. fats) & 7 & $6.7 \%$ \\
\hline d) Amount of Visceral adipose tissue (VAT) & 12 & $11.5 \%$ \\
\hline
\end{tabular}

4. When diagnosing obesity in children, which of the following tool is the best one to use?

\begin{tabular}{|l|c|c|}
\hline a) BMI curve & 35 & $33.7 \%$ \\
\hline b) Waist-to-hip ratio & 22 & $21.2 \%$ \\
\hline c) Iso-BMI curve & 7 & $6.7 \%$ \\
\hline d) Percentiles & 40 & $38.5 \%$ \\
\hline
\end{tabular}

5. Which of the patients would you most likely prioritize in terms of treatment for obesity?

\begin{tabular}{|l|c|c|}
\hline $\begin{array}{l}\text { a) Female } 38 \text { yrs old, BMI } 50 \mathrm{~kg} / \mathrm{m} 2 \text {. mild } \\
\text { hypertension, knee and LBP }\end{array}$ & 70 & $67.3 \%$ \\
\hline $\begin{array}{l}\text { b) Male } 34 \text { years old, BMI } 35 \mathrm{~kg} / \mathrm{m} 2 \text {, Diabetes } \\
\text { type 2, obstructive sleep apnea }\end{array}$ & 21 & $20.2 \%$ \\
\hline $\begin{array}{l}\text { c) Female } 48 \text { years old, BMI } 32 \mathrm{~kg} / \mathrm{m} \\
\text { physically active, small joint discomforts }\end{array}$ & 3 & $2.9 \%$ \\
\hline
\end{tabular}


d) Male 36 years old, BMI $45 \mathrm{~kg} /$, impaired 10

$9.6 \%$ fasting glucose, mild depression

6. Which statement in terms of reduction in body weight gives significant improvements in health?

\begin{tabular}{|l|c|c|}
\hline a) 10-15 kg WL & 43 & $41.3 \%$ \\
\hline b) 5-10\% WL from baseline weight & 33 & $31.7 \%$ \\
\hline $\begin{array}{l}\text { c) A reduction in BMI category (e.g. from WHO } \\
\text { class III to WHO class II) }\end{array}$ & 10 & $9.6 \%$ \\
\hline $\begin{array}{l}\text { d) A reduction in waist circumference (cm) by } \\
10 \%\end{array}$ & 18 & $17.3 \%$ \\
\hline
\end{tabular}

7. What is the most optimal strategy for lifestyle treatment of obesity?

\begin{tabular}{|l|c|c|}
\hline a) Changing dietary habits & 25 & $24.0 \%$ \\
\hline b) Combination of diet and exercise & 18 & $17.3 \%$ \\
\hline c) Increasing physical activity levels (PALS) & 20 & $19.2 \%$ \\
\hline d) Cognitive behavioral therapy (CBT) & 4 & $3.8 \%$ \\
\hline e) Combination of diet, exercise and CBT & 37 & $35.6 \%$ \\
\hline
\end{tabular}

8. When considering long-term weight reduction, which diet is the most effective one?

\begin{tabular}{|l|l|l|}
\hline a) Low carbohydrate-high fat (LCHF) & 37 & $35.6 \%$ \\
\hline b) Low fat & 26 & $25.0 \%$ \\
\hline c) Mediterranean diet & 17 & $16.3 \%$ \\
\hline $\begin{array}{l}\text { d) Any diet can give the same weight reduction } \\
\text { given equal negative energy balance and } \\
\text { long-term compliance }\end{array}$ & 24 & $23.1 \%$ \\
\hline
\end{tabular}

9. Which of the following statements is the most appropriate recommendation when looking at conservative treatment of obesity?

\begin{tabular}{|l|c|c|}
\hline $\begin{array}{l}\text { a) A negative energy deficit of approximately } \\
600 \mathrm{kcal} / \text { day }\end{array}$ & 19 & $18.3 \%$ \\
\hline $\begin{array}{l}\text { b) }<20 \% \text { of the energy in the clied cum from } \\
\text { Cuts a macronutrient }\end{array}$ & 7 & $6.7 \%$ \\
\hline c) A weight loss of $>1.0 \mathrm{~kg} /$ week & 28 & $26.9 \%$ \\
\hline d) A diet very low in energy $(<300 \mathrm{kcal} /$ day) & 50 & $48.1 \%$ \\
\hline
\end{tabular}

10. Which of the following statements is the most correct one when looking at long-term outcomes of surgical treatment of obesity (Gastric ByPass, GHPJ)?

\begin{tabular}{|l|c|c|}
\hline $\begin{array}{l}\text { a) GBP improves the metabolic risk profile, but } \\
\text { not primarily cardiovascular risk }\end{array}$ & 11 & $10.6 \%$ \\
\hline $\begin{array}{l}\text { b) } 15 \% \text { of patients experience suboptimal } \\
\text { weight loss or significant weight regain }\end{array}$ & 16 & $15.4 \%$ \\
\hline $\begin{array}{l}\text { c) GBP does not produce a more significant } \\
\text { WL after two years when compared to lifestyle } \\
\text { treatment of obesity }\end{array}$ & 17 & $16.3 \%$ \\
\hline $\begin{array}{l}\text { d) } 95 \% \text { of patients who undergo GBP respond } \\
\text { well when looking at WI. }\end{array}$ & 60 & $57.7 \%$ \\
\hline
\end{tabular}

11. Which of the following statements represents the most common complication after GBP?

\begin{tabular}{|l|c|c|}
\hline a) Hypertension & 6 & $5.8 \%$ \\
\hline b) Dyslipidemia & 8 & $7.7 \%$ \\
\hline $\begin{array}{l}\text { c) Low levels of vitamin B12, vitamin D, cal- } \\
\text { cium, and iron }\end{array}$ & 51 & $49.0 \%$ \\
\hline d) Osteoporosis & 39 & $37.5 \%$ \\
\hline
\end{tabular}

12. Which of the following comorbidities is least associated with obesity?

\begin{tabular}{|l|c|c|}
\hline a) DM & 10 & $9.6 \%$ \\
\hline b) Osteoporosis & 46 & $44.2 \%$ \\
\hline c) Male infertility & 32 & $30.8 \%$ \\
\hline d) Non-alcoholic fatty liver disease (NAFLD) & 16 & $15.4 \%$ \\
\hline
\end{tabular}

\section{Which level of physical activity is recommended to} maintain weight loss?

\begin{tabular}{|l|c|c|}
\hline a) $30 \mathrm{~min} /$ day moderate intensity & 41 & $39.4 \%$ \\
\hline $\begin{array}{l}\text { b) Short } 10 \text { min bouts with high intensity } 3 \\
\text { times/week }\end{array}$ & 22 & $21.2 \%$ \\
\hline c) $45-60 \mathrm{~min} /$ day moderate intensity & 24 & $23.1 \%$ \\
\hline d) 30 min High intensity 3 times/week & 18 & $17.3 \%$ \\
\hline
\end{tabular}

14. On average, which percentage do Individuals who have lost weight through lifestyle changes are able to maintain a clinically significant WL for at least 1 year!

\begin{tabular}{|l|c|c|}
\hline a) $20 \%$ & 62 & $59.6 \%$ \\
\hline b) $<10 \%$ & 6 & $5.8 \%$ \\
\hline c) $30 \%$ & 24 & $23.1 \%$ \\
\hline d) $40 \%$ & 12 & $11.5 \%$ \\
\hline
\end{tabular}

15. Which of the following statements is most associated with long-term WL maintenance?

\begin{tabular}{|l|c|c|}
\hline $\begin{array}{l}\text { a) A diet high in carbohydrates (55\% of total } \\
\text { energy intake) }\end{array}$ & 24 & $23.1 \%$ \\
\hline b) Exercising at high intensity > 3 times/week & 40 & $38.5 \%$ \\
\hline c) Eating breakfast 5 days/week & 33 & $31.7 \%$ \\
\hline d) Self-weighing I times/month & 7 & $6.7 \%$ \\
\hline
\end{tabular}

16. Choose the statement you agree the most with regarding possible reasons for you as a doctor feeling resistant to initialize treatment of obesity.

\begin{tabular}{|l|c|c|}
\hline $\begin{array}{l}\text { a) There is not much I can accomplish during a } \\
\text { 10-min consultation }\end{array}$ & 29 & $27.9 \%$ \\
\hline $\begin{array}{l}\text { b) Obesity is a very complex condition, so I } \\
\text { prefer to focus on treating the comorbidities }\end{array}$ & 24 & $23.1 \%$ \\
\hline $\begin{array}{l}\text { c) There are few economic incentives in } \\
\text { promoting public health/obesity prevention, } \\
\text { and it is difficult charging fees for suggesting } \\
\text { simple changes in diet and exercise routines }\end{array}$ & 4 & $3.8 \%$ \\
\hline
\end{tabular}




\begin{tabular}{|l|c|c|}
\hline $\begin{array}{l}\text { d) It is my duty to discuss weight issues with } \\
\text { the patient, but long-term follow-up and } \\
\text { frequent consultations are beyond my capacity } \\
\text { in busy practice }\end{array}$ & 20 & $19.2 \%$ \\
\hline $\begin{array}{l}\text { e) I believe that most patients with obesity } \\
\text { live in denial, and few methods are effective } \\
\text { in maintaining weight, so I give them general } \\
\text { advice and move on }\end{array}$ & 27 & $26.0 \%$ \\
\hline $\begin{array}{l}\text { 17. Choose the statement you agree the most with regard- } \\
\text { ing your role as a medical professional who treats patients } \\
\text { with obesity. }\end{array}$ & 27 & $26.0 \%$ \\
\hline $\begin{array}{l}\text { a) I trust my acquired knowledge from } \\
\text { university education, and I know how to treat } \\
\text { this patient }\end{array}$ & & \\
\hline $\begin{array}{l}\text { b) I prefer to refer the patient to tertiary care/ } \\
\text { specialist health care services because I } \\
\text { suggest that obesity is a self-inflicted condition } \\
\text { and it is beyond my reach to treat }\end{array}$ & 26 & $25.0 \%$ \\
\hline $\begin{array}{l}\text { c) I can handle treating the medical aspects of } \\
\text { comorbidities, but not the complexity of the } \\
\text { lifestyle issues }\end{array}$ & 11 & $10.6 \%$ \\
\hline $\begin{array}{l}\text { d) I fear that I may create poor doctor-patient } \\
\text { dynamics by bringing up weight and lifestyle } \\
\text { issues. The subject of body weight is such a } \\
\text { sensitive topic, and discussing it may make the } \\
\text { patient reluctant to keep me as their GP }\end{array}$ & 40 & $38.5 \%$ \\
\hline
\end{tabular}

Table 2: Physicians' insight into obesity.

criterion regarding obesity. However, when diagnosing obesity in children, percentiles (38.5\%) is the best tool, followed by the BMI curve $(33.7 \%)$, table 2 .

In terms of treatment for obesity, $87.5 \%$ of physicians most likely prioritize those obese cases with comorbid conditions like diabetes, obstructive sleep apnea, hypertension, knee and low back pain. In terms of reducing body weight, $73 \%$ of physicians see that $10-15 \mathrm{~kg}$ weight loss or $5-10 \%$ weight loss from baseline weight gives significant improvements in health, table 2 .

The most optimal strategy for lifestyle treatment of obesity is the combination of diet, exercise, and CBT (35.6\%) followed by changing dietary habits (24.0\%). A low carbohydrate-high fat diet is the most effective one when considering long-term weight reduction (35.6\%), table 2 .

When looking at the conservative treatment of obesity, a diet very low in energy $(<300 \mathrm{kcal} /$ day $)$ is the most appropriate rec- ommendation (48.1\%). In addition, when looking at long-term outcomes of surgical treatment of obesity (Gastric ByPass, GHPJ), $57.7 \%$ of physicians reported that $95 \%$ of patients who undergo GBP respond well when looking at WI. Low levels of vitamin B12, vitamin $\mathrm{D}$, calcium, and iron, in addition to osteoporosis, are the most common complication after GBP (49.0\% and 37.5\%), table 2 .

The most frequent recommended level of physical activity to maintain weight loss is $30 \mathrm{~min} /$ day moderate intensity (39.4\%) followed by 45-60 $\mathrm{min} /$ day moderate intensity (23.1\%). On average, $59.6 \%$ of physicians reported that $20 \%$ of Individuals who have lost weight through lifestyle changes could maintain a clinically significant WL for at least one year. In addition, 38.5\% of them mentioned that Exercising at high intensity $>3$ times/week is most associated with long-term WL maintenance, table 2. Almost 50\% of physicians have a wrong perception about weight loss maintenance.

About $27.9 \%$ of physicians are feeling resistant to initializing obesity treatment because there is not much they can accomplish during a 10 -min consultation. In addition, $26.0 \%$ believe that most patients with obesity live in denial, and few methods are useful in maintaining weight, so they give them general advice and move on. More than $95 \%$ of physicians believe that busy practice, short time of consultation, and disease complexity are the main barriers to start treating obesity.

Physicians' role

Regarding physicians' role as medical professionals who treat patients with obesity, around $38.5 \%$ of physicians fear that they may create low doctor-patient dynamics by bringing up weight and lifestyle issues. Bodyweight is such a sensitive topic, and discussing it may make the patient reluctant to keep them as their GP. However, $26.0 \%$ trust their acquired knowledge from university education and know how to treat this patient. While $25.0 \%$ of them prefer to refer the patient to tertiary care/specialist health care services because they suggest that obesity is a self-inflicted condition and beyond their reach to treat, only $10.6 \%$ of physicians reported that they could handle treating the medical aspects of comorbidities, but not the complexity of the lifestyle issues, table 2 .

\section{Patients' arm}

\section{Demographics}

Patients are from Kuwait (23.4\%), Bahrain (24.3\%), Qatar $(26.2 \%)$ and Oman $(26.0 \%)$. The majority of them $(70.1 \%)$ are local. Most $(82.1 \%)$ of the 2337 enrolled patients belong to $25-44$ 
Physicians and Patients' Awareness About the Risks, Impacts, and Management of Obesity in the Gulf Region; A Cross-sectional Study

years. Almost half of them were male (50.7\%). The majority, $75.1 \%$, are obese (BMI 30-35), and the rest, 24.91\%, are very obese (BMI > 35). Almost $47.5 \%$ of them have hypertension, $37.7 \%$ diabetes, $35.0 \%$ arthritis and $28.3 \%$ have high cholesterol / lipids. More than $60 \%$ of them have the last visit to their physician during the past three months, table 3 .

\begin{tabular}{|c|c|c|c|}
\hline & & $\mathbf{N}$ & $\%$ \\
\hline \multicolumn{2}{|l|}{ Sample size } & 2337 & \\
\hline \multirow[t]{4}{*}{ Country } & Kuwait & 548 & $23.4 \%$ \\
\hline & Bahrain & 569 & $24.3 \%$ \\
\hline & Qatar & 613 & $26.2 \%$ \\
\hline & Oman & 607 & $26.0 \%$ \\
\hline \multirow[t]{4}{*}{ Nationality } & Local & 1639 & $70.1 \%$ \\
\hline & Expat Arabs & 497 & $21.3 \%$ \\
\hline & Asians & 155 & $6.6 \%$ \\
\hline & Westerners & 46 & $2.0 \%$ \\
\hline \multirow[t]{8}{*}{ Age } & $18-24$ & 98 & $4.2 \%$ \\
\hline & $25-31$ & 551 & $23.6 \%$ \\
\hline & $32-37$ & 738 & $31.6 \%$ \\
\hline & $38-44$ & 629 & $26.9 \%$ \\
\hline & $45-51$ & 172 & $7.4 \%$ \\
\hline & $52-57$ & 105 & $4.5 \%$ \\
\hline & $58-62$ & 22 & $0.9 \%$ \\
\hline & $62+$ & 22 & $0.9 \%$ \\
\hline \multirow[t]{2}{*}{ Gender } & Male & 1185 & $50.7 \%$ \\
\hline & Female & 1152 & $49.3 \%$ \\
\hline \multirow[t]{2}{*}{ BMI } & $30-35$ & 1755 & $75.1 \%$ \\
\hline & $>35$ & 582 & $24.9 \%$ \\
\hline \multirow[t]{5}{*}{ Last visit } & Past month & 900 & $38.5 \%$ \\
\hline & $\begin{array}{l}\text { Past } 3 \\
\text { months }\end{array}$ & 662 & $28.3 \%$ \\
\hline & $\begin{array}{l}\text { Past } 6 \\
\text { months }\end{array}$ & 490 & $21.0 \%$ \\
\hline & Past year & 204 & $8.7 \%$ \\
\hline & $\begin{array}{l}\text { Do not } \\
\text { remember }\end{array}$ & 81 & $3.5 \%$ \\
\hline \multirow{4}{*}{$\begin{array}{l}\text { Other } \\
\text { conditions }\end{array}$} & Hypertension & 1109 & $47.5 \%$ \\
\hline & Diabetes & 881 & $37.7 \%$ \\
\hline & Arthritis & 818 & $35.0 \%$ \\
\hline & $\begin{array}{c}\text { High } \\
\text { cholesterol / } \\
\text { lipids }\end{array}$ & 661 & $28.3 \%$ \\
\hline
\end{tabular}

\begin{tabular}{|c|c|c|c|}
\hline & Heart disease & 483 & $20.7 \%$ \\
\hline & $\begin{array}{c}\text { Chronic } \\
\text { kidney } \\
\text { disease }\end{array}$ & 145 & $6.2 \%$ \\
\hline & Cancer & 105 & $4.5 \%$ \\
\hline & Others & 347 & $14.8 \%$ \\
\hline
\end{tabular}

Table 3: Patients' demographic and clinical data.

\section{Patients' insight into obesity}

More than $60 \%$ of them mentioned that obesity has a significant impact on their lifestyle. About 71\% reported that physical health had been impacted by obesity, and $67.0 \%$ mentioned that social life had been limited due to obesity. In addition, $82.0 \%$ see that romantic relationships have been limited because of obesity. Overall, $64.0 \%$ of reported that obesity has a significant effect on overall health.

More than half the patients reported that being obese increases the risk of developing arthritis, heart disease, fatty liver, hypertension, and kidney failure. In addition, more than half the patients think that heart diseases, hypertension, sleep apnea, diabetes, cerebral stroke, arthritis, kidney failure, and severe depression are the most significant outcomes of being overweight or obese, table 4.

About $78.0 \%$ of patients view that obesity is a lifestyle choice resulting from a persons' eating and exercise habits. More than half of the patients (59.0\%) obesity is a risk factor for other diseases, but it is not a disease itself, while the rest $(41.0 \%)$ see it as a disease itself.

More than the third of patients (36.0\%) see the dietitian, and $30.0 \%$ see the family physician. About the third of patients or more have ever been told by a physician that they are obese, their doctor has initiated a talk about weight before, and have spoken with a doctor or health professional about their weight, table 4 .

Patients perceived that obesity/overweight is less serious, with an average seriousness of $28.0 \%$ on a scale from 30 to $100 \%$. About $63.0 \%$ perceived that obesity is a cosmetic issue and $37.0 \%$ see it as a serious health issue. The worst fearful complication from obesity is heart disease (71.0\%), followed by diabetes $(60.0 \%)$ and arthritis (51.0\%), table 4 . 
Physicians and Patients' Awareness About the Risks, Impacts, and Management of Obesity in the Gulf Region; A Cross-sectional Study

\begin{tabular}{|c|c|c|}
\hline & $\mathbf{N}$ & $\%$ \\
\hline Sample size & 2337 & \\
\hline \multicolumn{3}{|c|}{ 1. To what extent does Obesity affect your lifestyle? } \\
\hline No effect & 327 & $14.0 \%$ \\
\hline Small effect & 538 & $23.0 \%$ \\
\hline Medium effect & 701 & $30.0 \%$ \\
\hline Some times & 304 & $13.0 \%$ \\
\hline All the time & 467 & $20.0 \%$ \\
\hline $\begin{array}{l}\text { 2. Has your physical health been impact- } \\
\text { ed by Obesity? (yes) }\end{array}$ & 1659 & $71.0 \%$ \\
\hline $\begin{array}{l}\text { 3. Has your social life been limited due to } \\
\text { obesity? (yes) }\end{array}$ & 1566 & $67.0 \%$ \\
\hline $\begin{array}{l}\text { 4. Have your romantic relationships been } \\
\text { limited because of obesity? (yes) }\end{array}$ & 1916 & $82.0 \%$ \\
\hline \multicolumn{3}{|c|}{$\begin{array}{l}\text { 5. To the best of your knowledge, does being obese in- } \\
\text { crease a person's risk of developing each of the following } \\
\text { or does not increase that risk? }\end{array}$} \\
\hline Heart disease & 1332 & $57.0 \%$ \\
\hline Hypertension & 1239 & $53.0 \%$ \\
\hline Sleep apnea & 748 & $32.0 \%$ \\
\hline Diabetes & 1145 & $49.0 \%$ \\
\hline Cerebral stroke & 631 & $27.0 \%$ \\
\hline Arthritis & 1472 & $63.0 \%$ \\
\hline Kidney failure & 1169 & $50.0 \%$ \\
\hline Severe depression & 982 & $42.0 \%$ \\
\hline Infertility in females & 397 & $17.0 \%$ \\
\hline Fatty liver & 1285 & $55.0 \%$ \\
\hline
\end{tabular}

\begin{tabular}{|l|l|l|}
\hline $\begin{array}{l}\text { Obesity is a disease resulting from many } \\
\text { different genetic, environmental, and social } \\
\text { factors }\end{array}$ & 514 & $22.0 \%$ \\
\hline
\end{tabular}

8. Which statement comes closest to your view of obesity, even if neither is exactly right?

\begin{tabular}{|l|l|l|}
\hline Obesity itself is a disease & 958 & $41.0 \%$ \\
\hline $\begin{array}{l}\text { Obesity is a risk factor for other diseases, but } \\
\text { it is not a disease itself }\end{array}$ & 1379 & $59.0 \%$ \\
\hline
\end{tabular}

9. Which physician specialty/ HCPS do you see?

\begin{tabular}{|l|l|l|}
\hline GP & 491 & $21.0 \%$ \\
\hline Family medicine & 701 & $30.0 \%$ \\
\hline Endocrinologist & 631 & $27.0 \%$ \\
\hline Obesity surgeon & 280 & $12.0 \%$ \\
\hline Health educator & 374 & $16.0 \%$ \\
\hline Dietitian & 841 & $36.0 \%$ \\
\hline Other & 238 & $10.2 \%$ \\
\hline
\end{tabular}

10. To the best of your knowledge, how much obesity affects a person's overall health?

\begin{tabular}{|l|l|l|}
\hline Big effect & 1496 & $64.0 \%$ \\
\hline Small effect & 841 & $36.0 \%$ \\
\hline 11. What is the role of physicians in education?
\end{tabular}

11. What is the role of physicians in education?

\begin{tabular}{|l|l|l|}
\hline $\begin{array}{l}\text { Have you ever told by a physician that you } \\
\text { are obese? (Yes) }\end{array}$ & 888 & $38.0 \%$ \\
\hline $\begin{array}{l}\text { Has your doctor ever initiated talk about } \\
\text { your weight before? (Yes) }\end{array}$ & 701 & $30.0 \%$ \\
\hline $\begin{array}{l}\text { Have you spoken with a doctor or health } \\
\text { professional specifically about your weight? } \\
\text { (Yes) }\end{array}$ & 818 & $35.0 \%$ \\
\hline
\end{tabular}

6. What do you think the most significant outcomes of being overweight or obese?

\begin{tabular}{|l|l|l|}
\hline Heart disease & 1309 & $56.0 \%$ \\
\hline Hypertension & 1285 & $55.0 \%$ \\
\hline Sleep apnea & 1332 & $57.0 \%$ \\
\hline Diabetes & 1192 & $51.0 \%$ \\
\hline Cerebral stroke & 1355 & $58.0 \%$ \\
\hline Arthritis & 1356 & $58.0 \%$ \\
\hline Kidney failure & 1308 & $56.0 \%$ \\
\hline Severe depression & 1285 & $55.0 \%$ \\
\hline Others & 1215 & $52.0 \%$ \\
\hline
\end{tabular}

7. Which statement comes closest to your view of obesity, even if neither is exactly right?

\begin{tabular}{|l|l|l|}
\hline $\begin{array}{l}\text { Obesity is a lifestyle choice resulting from a } \\
\text { persons' eating and exercise habits }\end{array}$ & 1823 & $78.0 \%$ \\
\hline
\end{tabular}

\begin{tabular}{|l|l|l|}
\hline \multicolumn{3}{|l|}{ 12. How serious each of these health issues? average } \\
\hline Obesity/overweight & $28.0 \%$ & \\
\hline Diabetes & $59.0 \%$ & \\
\hline Mental illness & $62.0 \%$ & \\
\hline Heart disease & $81.0 \%$ & \\
\hline Cancer & $95.0 \%$ & \\
\hline 13. How do you perceive obesity? & & \\
\hline Cosmetic issue & 1472 & $63.0 \%$ \\
\hline Serious health issue & 865 & $37.0 \%$ \\
\hline 14.
\end{tabular}

14. What is your worst fearful complication to have from obesity? \% With from the below related to obesity:

\begin{tabular}{|l|l|l|}
\hline Heart disease & 1659 & $71.0 \%$ \\
\hline Hypertension & 351 & $15.0 \%$ \\
\hline Sleep apnea & 210 & $9.0 \%$ \\
\hline
\end{tabular}




\begin{tabular}{|l|l|l|}
\hline Diabetes & 1402 & $60.0 \%$ \\
\hline Cerebral stroke & 397 & $17.0 \%$ \\
\hline Arthritis & 1192 & $51.0 \%$ \\
\hline Renal failure & 280 & $12.0 \%$ \\
\hline Other & 491 & $21.0 \%$ \\
\hline
\end{tabular}

15. Is each of the following a major barrier, a minor barrier, or not a barrier at all to your attempts to lose weight?

\begin{tabular}{|l|l|l|}
\hline Lack of power & 1776 & $76.0 \%$ \\
\hline I do not get enough support & 1916 & $82.0 \%$ \\
\hline $\begin{array}{l}\text { Healthy foods are not convenient, affordable, } \\
\text { or available enough }\end{array}$ & 1612 & $69.0 \%$ \\
\hline $\begin{array}{l}\text { Unhealthy foods are too convenient, } \\
\text { affordable, or available }\end{array}$ & 1870 & $80.0 \%$ \\
\hline $\begin{array}{l}\text { There are not enough safe or low-cost } \\
\text { options where I can be physically active }\end{array}$ & 1986 & $85.0 \%$ \\
\hline $\begin{array}{l}\text { I spend too much time in front of TV, video } \\
\text { games, or computer screens }\end{array}$ & 1542 & $66.0 \%$ \\
\hline $\begin{array}{l}\text { I am generally predisposed to be overweight } \\
\text { or obese }\end{array}$ & 1336 & $57.2 \%$ \\
\hline $\begin{array}{l}\text { I do not have enough information to know } \\
\text { how to manage my weight }\end{array}$ & 2103 & $90.0 \%$ \\
\hline Methods for losing weight are too expensive & 1916 & $82.0 \%$ \\
\hline $\begin{array}{l}\text { Methods for losing weight are not covered by } \\
\text { my health insurance }\end{array}$ & 2150 & $92.0 \%$ \\
\hline 16. Please check all methods you are curr & \\
\hline
\end{tabular}

16. Please check all methods you are currently using or have tried to use in the past to lose weight

\begin{tabular}{|l|l|l|}
\hline $\begin{array}{l}\text { Losing weight on your own through diet and } \\
\text { exercise }\end{array}$ & 1753 & $75.0 \%$ \\
\hline $\begin{array}{l}\text { Losing weight with the help of your doctor } \\
\text { through diet or exercise }\end{array}$ & 1402 & $60.0 \%$ \\
\hline $\begin{array}{l}\text { One-on-one dietary counselling with a dieti- } \\
\text { cian }\end{array}$ & 818 & $35.0 \%$ \\
\hline $\begin{array}{l}\text { Formal exercise programs with a personal } \\
\text { trainer, physical therapist, or occupational } \\
\text { therapist }\end{array}$ & 514 & $22.0 \%$ \\
\hline $\begin{array}{l}\text { Formal weight loss programs such as Weight } \\
\text { Watchers, Jenny Craig, Nutrisystem, LA } \\
\text { Weight Loss, or a hospital-based program }\end{array}$ & 677 & $29.0 \%$ \\
\hline Dietary supplements such as Herbal-life & 1542 & $66.0 \%$ \\
\hline Prescription medication & 1823 & $78.0 \%$ \\
\hline Meal replacement & 1402 & $60.0 \%$ \\
\hline $\begin{array}{l}\text { Weight loss surgery such as gastric bypass or } \\
\text { gastric sleeve surgery }\end{array}$ & 280 & $12.0 \%$ \\
\hline $\begin{array}{l}\text { Other treatments or methods such as online } \\
\text { support groups }\end{array}$ & 210 & $9.0 \%$ \\
\hline
\end{tabular}

Table 4: Patients' insights into obesity.
About $92.0 \%$ of patients reported that losing weight methods are not covered by their health insurance as a significant barrier to their attempts to lose weight, followed by a lack of information to manage weight (90.0\%). Other barriers are shown in table 4.

The most frequent methods that patients are currently using or have tried to use in the past to lose weight are prescription medication (78.0\%), losing weight on their own through diet and exercise (75.0\%), and dietary supplements such as Herbal-life (66.0\%), table 4 .

\section{Discussion}

The double-arms cross-sectional study was established to improve the understanding of physicians and obese patients' perception and awareness with regards to risks, impacts, and management of obesity. The study was carried out in the Gulf countries Kuwait, Bahrain, Qatar, and Oman.

The most frequent main modifiable reason for the increase in overweight and obesity, according to physicians, is the lack of selfcontrol. Reduction in motivation and lack of compliance is the most likely contributors to weight gain after a period of weight loss. More than half of the enrolled physicians reported that BMI represents the current standard diagnostic criterion regarding obesity. Also, physicians see that $10-15 \mathrm{~kg}$ weight loss or $5-10 \%$ weight loss from baseline weight gives significant health improvements in terms of reducing body weight. In terms of treatment for obesity, $87.5 \%$ of physicians most likely prioritize those obese cases with comorbid conditions like diabetes, obstructive sleep apnea, hypertension, knee and low back pain. The most optimal lifestyle treatment strategy for obesity is diet, exercise, and CBT, followed by changing dietary habits. A low carbohydrate-high fat diet is the most effective one when considering long-term weight reduction. When looking at the conservative treatment of obesity, a diet very low in energy ( $<300 \mathrm{kcal} /$ day) is the most appropriate recommendation.

The most frequent recommended level of physical activity to maintain weight loss is $30 \mathrm{~min} /$ day moderate intensity followed by 45-60 min/day moderate intensity. On average, most physicians reported that $20 \%$ of individuals who have lost weight through lifestyle changes could maintain a clinically significant weight loss for at least one year. Exercising at high intensity $>3$ times/week is most associated with long-term weight loss maintenance. Besides, when looking at long-term outcomes of surgical treatment of obesity (Gastric ByPass, GHPJ), physicians reported that patients who undergo GBP respond well when looking at WI. Low levels of vitamin B12, vitamin D, calcium, and iron, in addition to osteoporosis, are the most common complication after GBP. 
The results of this study showed that not all physicians believe that they have a responsibility to contribute to their patient's successful weight loss efforts actively. The greater part of the physicians was not aware of their role to educate people with obesity. Physicians believe that busy practice, short time of consultation, and disease complexity are the main barriers to treating obesity. Health care providers should emphasize increasing the patients' awareness about their disease and involve them in making decisions regarding their treatment choices.

More than half of the physicians think that community, focused group and public awareness and educational programs tailored to people with obesity help weight management. However, more than $70 \%$ of physicians claim that patient-focused training and education during the first year of their obesity management is essential. Therefore, awareness campaigns and strong partnerships are necessary to help improving disease awareness. Partnerships with patient groups, hospitals, and health associations to increase awareness of complications of obesity are necessary. Support local community partners to run screening, awareness, and counseling programs to empower people to safeguard and manage their health.

From the obese patients' perspective, more than half of them mentioned that obesity impacts their lifestyle, physical health, social life, and romantic relationships. Obesity has a significant effect on their overall health. More than half the patients reported that being obese increases the risk of developing significant outcomes like arthritis, heart disease, fatty liver, hypertension, and kidney failure. The majority of patients view that obesity is a lifestyle choice resulting from a persons' eating and exercise habits.

About $41.0 \%$ of the patients see that obesity is a disease itself. About a third of patients see a dietitian or family physician for their obesity.

On the other hand, physicians are reluctant to initiated talk about weight with patients. Patients perceived that obesity/overweight is less serious. They found it as a cosmetic issue. The worst fearful complication from obesity is heart disease, followed by diabetes and arthritis. Financial issues are significant barriers to attempts to lose weight, followed by lack of information. Prescription medications are the most frequent methods that patients are currently using or have tried to use in the past to lose weight, followed by diet and exercise and dietary supplements.
On the other hand, around $28 \%$ of patients believe they are incredibly knowledgeable about obesity. While there is a stated acknowledgment that stroke and heart disease are serious diseases, a small portion of patients recognizes a link between them and obesity. Patients' worst fear is quite distributed. Although patients with obesity see that stroke, heart diseases, and attacks are very serious; they rarely relate them to obesity. The majority of patients suffer from comorbidities like obesity and hypertension and do not necessarily have a balanced diet, thus not perceiving themselves as having a healthy lifestyle. There is a gap when it comes to obesity awareness and causes of obesity. Further awareness needs to be spread regarding the necessity of a healthy lifestyle for patients with obesity and the consequences of not doing so. Many patients admit that not being knowledgeable about obesity highlights the value a patient awareness campaign will provide.

Patients mostly mention heart diseases, sleep apnea, and arthritis as the main consequences of obesity on the total level. However, when looking at those who see themselves as high-risk patients, higher mentions of heart diseases can be observed. Patients' worst fear of obesity is quite different, and some are afraid of death, whereas others are worried about Diabetes and Hypertension. Clearer guidance is needed to know health issues associated with obesity, enabling people to more readily associate it with heart diseases and other complications. More effective and relevant channeling is needed to communicate heart diseases related events.

When it comes to the perceived seriousness of obesity, most patients do not see it as a serious disease itself. However, when looking at CV diseases like stroke, heart attack, and heart disease, patients consider them significantly more serious. Heart diseases are not yet identified as a health issue associated with obesity. A link needs to be made between obesity and heart diseases. Patient awareness programs will increase awareness and, in turn, the perception of the seriousness of obesity. Patients perceive diabetes to be more serious than obesity confirms that increasing public awareness about a specific disease alters their perception.

\section{Conclusion}

Doctors have an essential role to play in educating patients on different risks associated with obesity, where patients who have had this discussion with their physicians are the ones who are aware of the risk. Patients do not fully understand the seriousness of the risks associated with obesity. Doctors need to be encouraged to treat obesity and educate their patients on the associated risk. 


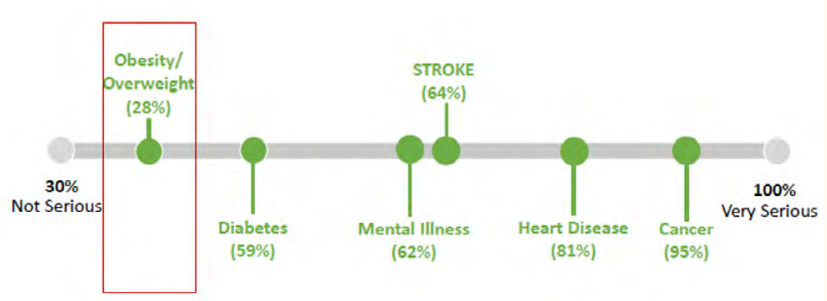

Figure 1: Patients' perception of obesity seriousness.

The language used should reflect the seriousness of the risk associated with obesity to ensure that patients acknowledge and relate this risk to themselves. A campaign needs to use the physicianpatient relationship, specifically GPs and family medicine, who see most patients.

\section{Disclaimer}

This Publication is financially funded by Novo Nordisk. The authors take full responsibility for the content and conclusions stated in this manuscript. Novo Nordisk neither influenced the content of this publication nor was it involved in the data collection, analysis, interpretation or review.

\section{Bibliography}

1. Peeters A. "Obesity in Adulthood and Its Consequences for Life Expectancy: A Life-Table Analysis". Annals of Internal Medicine 138.1 (2003): 24.

2. World Health Organization. Obesity (2016).

3. ALNohair S. "Obesity in Gulf countries". International Journal of Health Sciences and Research 8.1 (2014): 79-83.

4. Balhareth A., et al. "Overweight and obesity among adults in the Gulf States: A systematic literature review of correlates of weight, weight-related behaviours, and interventions". Obesity Review 20.5 (2014): 763-793.

5. Alqarni Saad. "A Review of Prevalence of Obesity in Saudi Arabia”. Journal of Obesity and Eating Disorders (2016).

6. Dillinger Jessica. "The Most Obese Countries In The World". WorldAtlas (2018).

7. WHO KSA Health profile (2015).
8. Ministry of Health Kingdom of Saudi Arabia. Survey of health information in the Kingdom of Saudi Arabia 2013. Riyadh: Ministry of Health Kingdom of Saudi Arabia; 2013. In WHO KSA Health profile (2015).

9. Kleiser C., et al. "Potential determinants of obesity among children and adolescents in Germany: results from the cross-sectional KiGGS study". BMC Public Health 9.1 (2009): 46.

10. Koyuncuoğlu Güngör N. "Overweight and Obesity in Children and Adolescents". Journal Of Clinical Research In Pediatric Endocrinology 6.3 (2014): 129-143.

11. Zammit C., et al. "Obesity and respiratory diseases". International Journal of General Medicine 3 (2010): 335-343.

12. Marinou Kyriakoula., et al. "Obesity and cardiovascular disease: From pathophysiology to risk stratification". International Journal of Cardiology 138 (2009): 3-8.

13. Williams E., et al. "Overweight and Obesity: Prevalence, Consequences, and Causes of a Growing Public Health Problem". Current Obesity Reports 4.3 (2015): 363-370.

14. Withrow D and Alter DA. "The economic burden of obesity worldwide: a systematic review of the direct costs of obesity". Obesity Reviews 12.2 (2011): 131-141.

\section{Assets from publication with us}

- Prompt Acknowledgement after receiving the article

- Thorough Double blinded peer review

- Rapid Publication

- Issue of Publication Certificate

- High visibility of your Published work

Website: www.actascientific.com/

Submit Article: www.actascientific.com/submission.php

Email us: editor@actascientific.com

Contact us: +919182824667 